\title{
A numerical analysis of a concrete slab breaching using high explosives
}

\section{Perfuração de placa de concreto por alto explosivo: uma análise numérica}
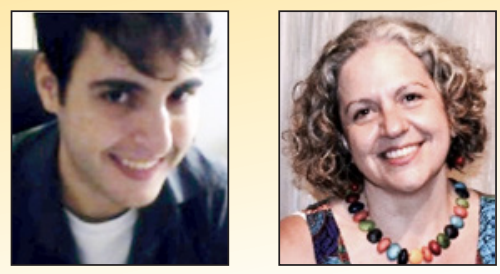

M. L. COSTA NETO a eng_murilolimeira@hotmail.com https://orcid.org/0000-0001-8146-4883

G. N. DOZ a

graciela@unb.br https://orcid.org/0000-0001-6428-4012

\begin{abstract}
Explosive breaching of walls, demolition of buildings with high structural robustness and non-programmed explosions may be extremely dangerous, the high risk of these events demands continuous researches to support the development of optimized constructive techniques and design. In this context, this work presents a numerical study of the explosive breaching of concrete wall using an optimized contact explosive charge with cilindrical shape, the CFD software Autodyn $₫$ Ansys was used. The results were evaluated in terms of damage pattern of the concrete slab, where was considered the cratering dimensions, the breakthrough hole and concrete spalling. A significant gain of the destructive potential of the explosive was observed by the simple rearrangement of its dimensions when compared to the base model, also the robustness of software to model and simulate a complex experiment that involves the detonation of a contact explosive charge was verified.
\end{abstract}

Keywords: explosion, concrete, computational fluid dynamics.

\section{Resumo}

Invasão de perímetros com explosivos, demolições de estruturas robustas e incidentes envolvendo explosões não-programadas podem ser extremamente perigosos. A gravidade destes eventos demanda estudos que possam levar a um conhecimento mais profundo do fenômeno explosão e de sua interação com elementos estruturais. Este trabalho apresenta uma análise numérica da otimização geométrica de um explosivo cilíndrico a base de TNT na perfuração de uma placa de concreto, utilizando o software Autodyn $®$ Ansys. Os resultados foram avaliados em termos do padrão de dano produzido na placa, sendo estudadas a profundidade e as dimensões da região da cratera e de lascamento. Quanto à proposta de otimização, observou-se um ganho importante no potencial destrutivo do explosivo pelo simples rearranjo de suas dimensões, também se constatou a aplicabilidade do software em se replicar numericamente um experimento envolvendo explosões por contato.

Palavras-chave: explosão, concreto, fluidodinâmica computacional.

Universidade de Brasilia, Departamento de Engenharia Civil e Ambiental, Brasília, DF, Brasil. 


\section{Introduction}

The detonation of contact charges is commonly used to breach concrete elements, demolition of old structures and military operations in urban terrain. Due the risks involved and high applicability of this phenomena it became target of new researches, such as those developed by [1], [2], [3], [4], [5], [6], [7] and [8].

In these researches was observed a search for more knowledge of the close blast effects. This kind of event is more dangerous to structural elements than regular far-field explosions.

Considering close explosions, the applicability of breaching technique show itself as a powerful tool when the detonation has proximity to key structural elements or other urban structures that significantly restricts the use of large demolition charges. The suitable positioning of the explosive along the element to be breached and the determination of its mass are important factors considering an optimized application of the detonation energy and the safeness of nearby structural elements. It is important to mention the contributions of Akers et al. [2] who developed numerical procedures and experiments to evaluate the damage to a reinforced concrete wall by the detonation of a C4 explosive device positioned on its surface. Remennikov et al. [9] analyzed the theoretical aspects of the contact explosions, presenting a formulation to predict the damage of this kind of event. Yue et al. [10] developed an analytical analysis to evaluate the damage on a concrete slab, considering a spherical-shaped explosive of TNT. Considering the risks and costs involved in experimental approaches to study this kind of phenomenon, the numerical simulations emerge as efficient and safe alternative. The use of computational fluid dynamics technology for modeling explosions, impacts and damage assessment is relatively recent, some works as presented by [8], [11], [12], [13] and [14], for example, show the applicability of this numerical tool.

In this context, this work presents a numerical study involving the detonation of cylindrical explosives on a simple concrete slab, aiming the evaluation of the explosion energy optimization for breaching proposal.
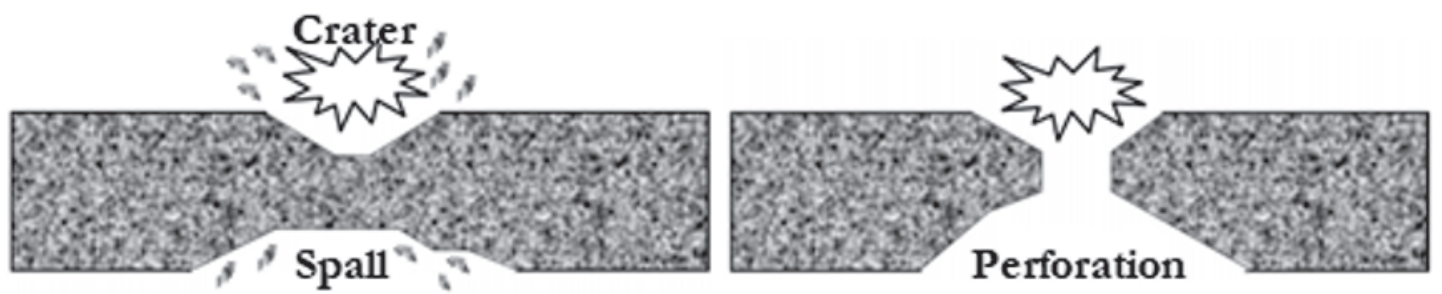

The optimization of explosive geometry proposed in this work was developed based on the prediction formulations proposed by $\mathrm{Re}$ mennikov et al. [9]. From these, a formulation is adjusted in order to relate the diameter of the explosive and its thickness, considering these values to analyze the thickness of the slab to be breached.

Therefore, it is possible to relate the dimensions of the explosive charge with the thickness of the concrete slab, abling a way to aim the most optimized relation.

To verify the optimization proposal, the experiments developed by Beppu et al. [15] was used. These experiments consist in a detonation of $\mathrm{C} 4$ cylindrical charge on a concrete slab. It is important to note that Remennikov et al. [9] also used this same experimental work to verify the applicability of its proposition.

Therefore, in addition to the original work proposal, it is possible to compare the numerical results obtained with the experimental results from Beppu et al. [15] and the analytical results of Remennikov et al. [9]. This allows an important analysis of the numerical tool's versatility in performing a simulation of a high complexity real event.

\section{Basic concepts of contact explosions}

The mass of explosive charge and the standoff distance are useful parameters in a blast damage prediction analysis. The detonation of charges in medium and large distances of the target produces shock waves that tends to engulfs the entire building and results in a more uniform loading. But, contact or close-range explosions provides a more concentrated energy distribution that results in a local damage.

The high level of stress transmitted to a structural element due a contact detonation produces a localized crushing and shattering effect on the material know as brisance [16].

When a shock wave produced by an explosive interact with a solid material, part of the blast wave energy is reflected due the difference of the material mechanical impedance, another part of this energy propagates through the material as a stress wave. This wave propagates through the structural element until it reach the back face and be reflected again. In the reinforced concrete elements, this second

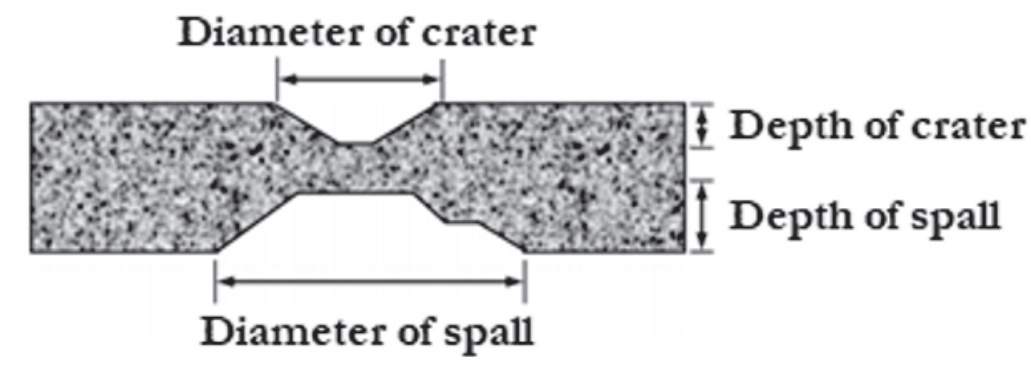

\section{Figure 1}

Damage pattern and important dimensions of a contact explosion, Beppu et al. [15] 
reflection leads to a tension rebound from the back face that results in concrete spalling. The damaged concrete fails due tension stress and its particles are ejected from the back surface [17], as show in the Figure 1.

\section{Experimental model}

The numerical models were based on the experiment developed by Beppu et al. [15] where the test specimens were a $500 \mathrm{~mm}$ side and $80 \mathrm{~mm}$ thick square concrete slab, subjected to the detonation of $46 \mathrm{~g}$ of $\mathrm{C} 4$ positioned in the center of the plate.

The concrete used has a compressive strength of $28.9 \mathrm{MPa}$.

The authors reported that the explosive used in the experiments has a cylindrical shape, the diameter of which is approximately equal to the thickness.

However, the exact specific mass of the explosive used in the experiment was not given, so, for the calculation of $\mathrm{C} 4$ cylinder dimensions, a specific mass of approximately $1.6 \mathrm{~g} / \mathrm{cm}^{3}$ [18] was considered, a value similar to that presented by Dobratz [19] and commonly shown in catalogs of demolition explosives.

In this work, the aspects of cratering damage (region in contact with the explosive) and spalling (posterior wall region) were evaluated.

\section{Theoretical analysis}

Considering that process of explosive charge detonation is instantaneous and it results in an impulsive loading, Remennikov et al. [9] proposed the formulation presented in Eq. 1.

$C=\frac{\mathrm{K}_{0} n^{2} h^{3}}{\mu}$

where $C$ is the mass of explosive in $\mathrm{kg}$ of TNT, $\mathrm{h}$ is the thickness of the slab or wall, $\mu$ is a shape factor related to the geometry of the explosive (cylindrical or prismatic), $\mathrm{n}$ is the spalling coefficient defined by Eq. 2 and $\mathrm{K}_{0}$ relates the properties of the explosive and the target. $K_{0}$ can be defined as the specific mass of explosive necessary to destruction of $1 \mathrm{~m}^{3}$ of material. $n=\frac{X}{h}+\tan \alpha$

According to Remennikov et al. [9], in Eq. 2 that is suitable to cy-

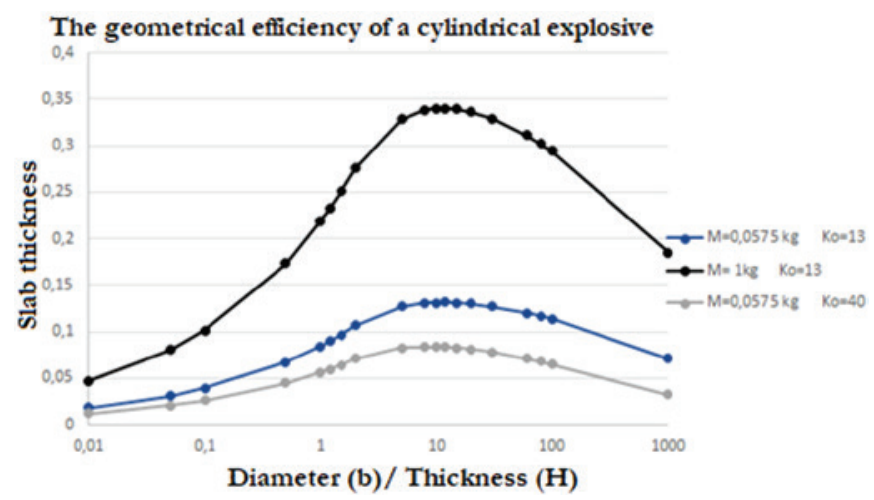

Figure 2

Geometric efficiency of cylindrical explosives based on the Remennikov et al. [9] formulation lindrical explosives, it is possible to consider a equal to $45^{\circ}$ and $\mathrm{X}$, which is the minimum radius of the pulse application area, as shown in the following Eq. 3.

$$
\begin{cases}X=\frac{b-H}{2}, & \text { when } \frac{b}{H} \geq 2 \\ X=\frac{b}{4}, & \text { when } \frac{b}{H} \leq 2\end{cases}
$$

Where $\mathrm{b}$ and $\mathrm{H}$ are the diameter and thickness of the explosive, respectively.

Rearranging the terms of the formulae proposed by Remennikov et al. [9], it is possible to define a third degree polynomial as a function of h, as shown in Eq. 4. It is important to note that this expression is applicable only to cylindrical explosives.

$h^{3}+(b-H) \cdot h^{2}+\left(\frac{b-H}{2}\right)^{2} \cdot h-\frac{C}{K_{0}}\left(1-2 \frac{H}{b}+\frac{4}{3} \frac{H^{2}}{b^{2}}\right)=0$

In the previous equation, by fixing the mass of explosive $C$ and changing the relations of $\mathrm{b}$ and $\mathrm{H}$ it is possible to find different values for $h$. This enabled a way to maximize the value of $h$ (thickness of the wall to be breached) by optimizing the relation between the explosive dimensions.

Figure 2 shows a graphical representation of Eq. 4 for different geometrical relations, the horizontal axis is in logarithmic scale. In order to plot the results, firstly an explosive charge with $0,0575 \mathrm{~kg}$ was considered and $\mathrm{K}_{0}$ was varied between 13 and 40 (plane and reinforced concrete), then the mass of the explosive was varied to $1 \mathrm{~kg}$ (mass value much higher than previously considered) with a $\mathrm{K}_{0}$ value of 13 .

The last graph showed a specific region in which the ratio between the diameter and the thickness of the explosive is optimized for breaching thicker concrete slabs, for a same mass of explosive. Thus, the diameter $(b)$ and the thickness $(H)$ ratio values $(b / H)$ situated between 9 and 12 showed an optimal behavior for breaching. According to the previous graph, the terminology optimized region for breaching will be used in this work to refer to the explosive diameter and thickness ratio that presents a better performance for breaching concrete slabs.

Demolition manuals [20] suggest the use of explosive charges in which the cross-sectional dimensions of this are greater than the thickness, this indicates that the assumption made from the graph has a reliable applicability. The efficiency of a rearrangement of the explosive charge geometry for a better energetic use of the explosion for breaching slabs will be evaluated numerically in this work.

\section{Numerical modelling}

The numerical simulations developed in this work were modeled in Ansys Autodyn software [18]. In this explicit analysis software, it is possible to model and simulate dynamic nonlinear problems involving impacts, penetration and explosions.

The software Autodyn [18] run simulations by the solution of conservation equations. During a simulation, the equations of mass, momentum and energy coupled with materials properties descriptions are solved simultaneously in each timestep [21]. In this context, for the model discretization an equation of state that relates the density and the internal energy with the pressure and a constitutive relation 


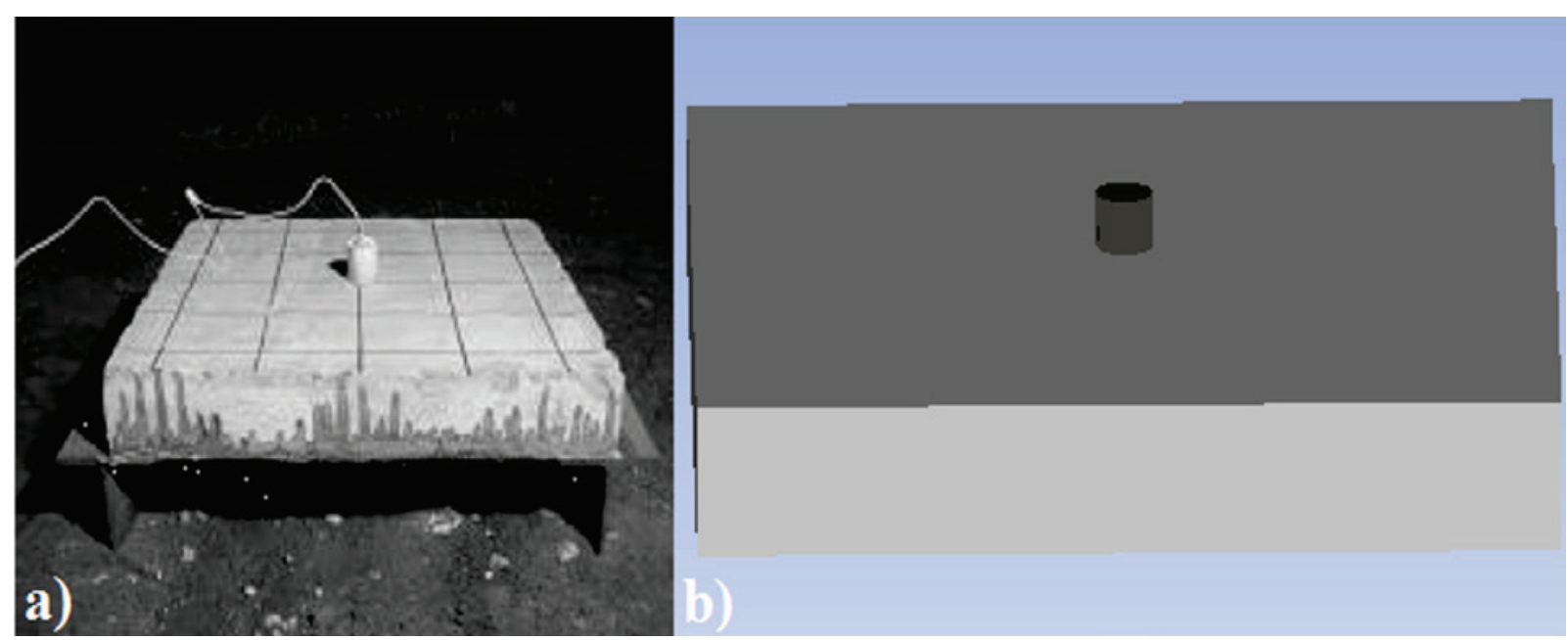

Figure 3

a) Experiment developed by Beppu et al. [15], b) numerical model from Autodyn [18]

that, basically, relates the tension in the material with the distortion of this one, [22] are used.

A set of numerical processors that can be applied to model different regions of the same problem is available [23] in Autodyn.

These processors have some differences between them, so that none of them alone can handle all the complexity of an entire explosion event and its interaction with a structure. Thus, a properly use of these processors are necessary to develop suitable models. In the models, volume elements were used and two different processors were applied to define the solid and fluid regions. The Lagrangian processor was used in the calculations of solids (concrete) and the Eulerian in the fluids (air and combustion process of the explosive). It was enabled the interaction between these two distinct kinds of discretization, allowing a proper simulation of the interaction between the detonation products and the concrete slab. The simulations performed in this work were modeled in a computer with a $3 \mathrm{GHz}$ 15-7400 processor and $16 \mathrm{~GB}$ of RAM. To process $2 \mathrm{~ms}$ of each model with a mesh refinement of $1 \mathrm{~mm}$ was necessary approximately 3 weeks of computational work.

\subsection{Numerical models}

The simulations developed consist in the modeling of a concrete slab subjected to a detonation of a C4 cylindrical charge on its surface. The concrete slab is positioned on steel supports as the basis experiment [15].

Five simulations were performed in this work, the first and second simulations are similar to the experiments developed by Beppu et al. [15]. These were modeled to verify the influence of the mesh refinement in results accuracy, damage pattern and the computational reproducibility of the experiment, using meshes of $5 \mathrm{~mm}$ and $1 \mathrm{~mm}$, respectively.

The Figure 3 shows the experimental model next to the developed numerical model. It is important to remember that in these cases it was considered a cylindrical explosive charge with a diameter and thickness of $34 \mathrm{~mm}$ and $33 \mathrm{~mm}$, respectively. The thickness of the concrete slab is $80 \mathrm{~mm}$.
In the third simulation, the proposed optimized region for breaching was evaluated. The modeling was performed using a $1 \mathrm{~mm}$ mesh refinement and a cylindrical explosive $\mathrm{C} 4$ charge with a diameter and thickness of $74 \mathrm{~mm}$ and $7 \mathrm{~mm}$, respectively. The concrete slab used in this model is the same as the previous simulations and it is identical to the one that was used in the experiment.

In the fourth simulation, a concrete slab identical to that was used in the previous models was modeled. However, the detonated explosive charge has the ratio between the diameter and the thickness completely outside of optimized region for breaching, it has diameter and thickness of $15.8 \mathrm{~mm}$ and $155 \mathrm{~mm}$, respectively. In the fifth simulation, a concrete slab similar to the previous models was considered, except for the thickness that is $122 \mathrm{~mm} \mathrm{(53 \%}$ thicker than the slab used in previous cases). This slab was subjected to a detonation of the same explosive used in the third model (the optimized explosive).

The thickness of the concrete plate developed in the fifth simulation was estimated from the Remennikov et al. [9] proposal.

\subsection{Constitutive modeling}

The simulated models demanded a modelling of some materials, such as concrete, C4 and air. Computational fluid dynamics technology requires an equation of state for the definition of materials, in addition to the constitutive models.

The ideal gas state equation of state was used for air, Eq. 5 .

$P=(\gamma-1) \rho e$

\section{Table 1}

Properties of air

\begin{tabular}{ccc}
\hline & Air & \\
\hline$\gamma$ & 1.40 \\
Specific mass & $0.001225 \mathrm{~g} / \mathrm{cm}^{3}$ \\
Temperature & $288.2 \mathrm{~K}$ \\
Specific heat & $717.599976 \mathrm{~J} / \mathrm{kgK}$ \\
\hline
\end{tabular}


Table 2

Properties of $\mathrm{C} 4$

\begin{tabular}{cc}
\hline & C4 \\
\hline Specific mass & $1,601 \mathrm{~g} / \mathrm{cm}^{3}$ \\
$\mathrm{C}_{1}$ & $6,097710^{8} \mathrm{kPa}$ \\
$\mathrm{C}_{2}$ & $1,29510^{7} \mathrm{kPa}$ \\
$\mathrm{R}_{1}$ & 4.5 \\
$\mathrm{R}_{2}$ & 1.4 \\
$\omega_{c \circ}$ & 0.25 \\
Detonation velocity & $8,19300110^{3} \mathrm{~m} / \mathrm{s}$ \\
Energy C-J & $9,00000110^{6} \mathrm{~kJ} / \mathrm{m}^{3}$ \\
Pressure C-J & $2,08000010^{7} \mathrm{kPa}$ \\
\hline
\end{tabular}

In the previous equation, $y$ is the adiabatic exponent, $\rho$ is the specific mass of the air and $e$ is the internal energy. The boundary conditions employed to the air allowed the simulation of a continuous medium, so when the shock wave reaches the model boundary it was not reflected. The air properties are shown in Table 1.

The equation of state JWL was used to describe the combustion and expansion process of $\mathrm{C} 4$ detonation products, Eq. 6 . The properties of $\mathrm{C} 4$ are shown in Table 2.

$P_{h}=C_{1} \cdot\left(1-\frac{\omega_{c o}}{R_{1} V_{e}}\right) e^{-R_{1} V_{e}}+C_{2} \cdot\left(1-\frac{\omega_{c o}}{R_{2} V_{e}}\right) e^{-R_{2} V_{e}}+\frac{\omega_{c o} E_{i}}{V_{e}}$

Where, $\mathrm{P}_{\mathrm{h}}$ is the hydrostatic pressure, $\mathrm{C}_{1}, \mathrm{C}_{2}, \mathrm{R}_{1}, \mathrm{R}_{2}$ and $\omega_{\mathrm{co}}$ are empirically derived constants related to the type of explosive used, $V_{e}$ is the ratio between the specific volume of detonation products and the specific volume of undetonated explosive. $E_{i}$ is the specific internal energy.

The P-alpha equation of state [24] was used for the concrete modeling and the RHT model was used to define strength and failure.

Considering that when a porous material subjected to a certain level of hydrostatic pressure begins to deform plastically, its density changes and, during this process, a certain amount of energy is absorbed, an equation of state that involves this phenomenon is required [25].

Thus, the use of the P-alpha equation of state is useful because it allows a suitable representation of the behavior of porous materials subjected to high stress levels [26]. This equation of state for fully compacted materials for $p \geq 0$ and $p<0$ is presented in the formulations shown in Eq.7 and Eq.8, respectively. Eq.9 presents this equation of state considering a porous material $(p \geq 0)$ :

$\mathrm{p}=A_{1} \mu+A_{2} \mu^{2}+A_{3} \mu^{3}+\left(B_{0}+B_{1} \mu\right) \rho_{0} \mathrm{e}$

$\mathrm{p}=T_{1} \mu+T_{2} \mu^{2}+B_{0} \rho_{0} \mathrm{e}$

$\mathrm{p}=A_{1} \bar{\mu}+A_{2} \bar{\mu}^{2}+A_{3} \bar{\mu}^{3}+\left(B_{0}+B_{1} \bar{\mu}\right) \rho_{0} \mathrm{e}$

\section{Table 3}

Properties of concrete

\begin{tabular}{cc}
\hline \multicolumn{2}{c}{ Concreto } \\
\hline Specific mass & $2.50 \mathrm{~g} / \mathrm{cm}^{3}$ \\
Compressive strength & $28.9 \mathrm{MPa}$ \\
Specific heat & $654 \mathrm{~J} / \mathrm{kgK}$ \\
\hline
\end{tabular}

Table 4

Results of experimental, numerical and analytical analysis

\begin{tabular}{cccc}
\hline Model & $\begin{array}{c}\text { Crater } \\
\text { diameter } \\
(\mathbf{m m})\end{array}$ & $\begin{array}{c}\text { Spall } \\
\text { diameter } \\
(\mathbf{m m})\end{array}$ & $\begin{array}{c}\text { Crater } \\
\text { depth } \\
(\mathbf{m m})\end{array}$ \\
\hline Beppu et al. [15] & $130-160$ & 210 & $20-28$ \\
10 Simulation (5 mm) $^{\circ}$ & 100 & 180 & 20 \\
$2^{\circ}$ Simulation (1 mm) & 106 & 200 & 20 \\
Remennikov et al. [9] & 204 & 195 & 21 \\
\hline
\end{tabular}

Where, $p$ is the pressure, $\rho_{o}$ is the initial density, $A_{n}, B_{n}$ and $T_{n}$ are material constants, $e$ is the internal energy, $\mu$ is the relative volume change for the cases of fully compacted and porous material. Table 3 presents the properties used for concrete.

A suitable modeling of solids subjected to high intensity loads such as those coming from a contact explosion need erosion models to handle the large distortions presented by the Lagrangian mesh [27], in this work, the effective instantaneous geometric strain model with strain limit of 0.5 was used.

The supports used in the experiment were applied in the numerical model as boundary conditions that restricted vertical movement.

\section{Results and discussion}

\subsection{First and second simulation}

The first two simulations were based on the work developed by Beppu et al. [15]. The numerical reproducibility of the experiment and the performance of the $5 \mathrm{~mm}$ and $1 \mathrm{~mm}$ mesh refinements are evaluated.

The Table 4 presents the results obtained numerically in comparison with those obtained by Beppu et al. [15] and those estimated through the Remennikov et al. [9].

The numerical results obtained for the crater depth showed a good accuracy with the experimental ones, the same can be observed for the diameters of the cratering region and spalling region as can be seen in Figure 3. In this figure, a damage color scale is used, where 0 (blue color) represents the undamaged material and 1 the complete failure (red color).

The Figure 4 shows the damage pattern presented by the numerical simulation with that presented by the experiment, being possible to observe many similarities.

Considering meshes refinement It is possible to affirm that a greater refinement resulted in a more precise definition of the damage region. The small differences between the experimental and numerical results may be related to the conditions of the concrete in situ or with some specifications of the models, for example, a greater refinement would probably bring more accurate results.

The 2 ms simulated for each model were sufficient to evaluate the presented damage pattern, in this time of simulation no further increases were observed to the damage caused and the kinetic energy of the elements was already very reduced. However, more simulation time would be necessary to define the final dimensions of the produced whole, which can be computationally expensive in explicit analysis software. 


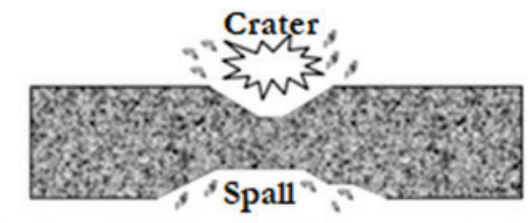

a)
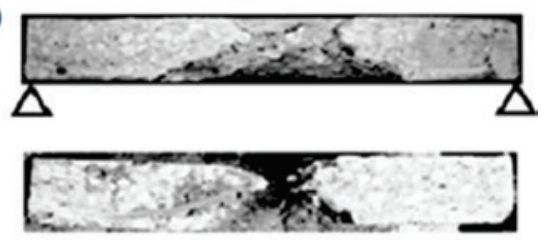

b)

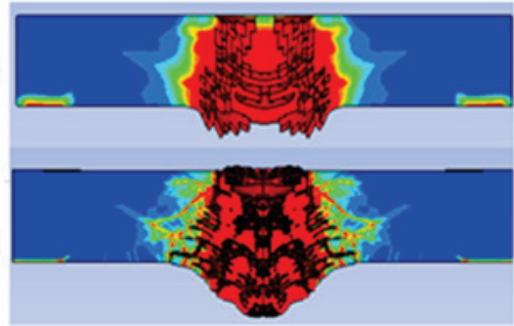

\section{Figure 4}

Experimental tests from Beppu et al. [15],

b) $1^{\circ}$ Simulation at $2 \mathrm{~ms}$ ( $5 \mathrm{~mm}$ mesh refinement) and c) $2^{\circ}$ simulation at $2 \mathrm{~ms}$ ( $1 \mathrm{~mm}$ mesh refinement)

\subsection{Third and fourth simulation}

In these simulations the performance of the "optimized region for breaching" proposal was evaluated, using the base experimental model as parameter. In these simulations the third and fourth models presents an explosive with "optimized" dimensions and an explosive with dimensions outside the optimal relation, respectively. Table 5 presents the results found for these models in comparison to the experimental model considered as comparative parameter. The results showed the influence of the explosive geometry on the level of damage in the concrete slab, it was verified that the rearrangement of the explosive dimensions was enough to significantly increase its destructive power.

In terms of breaching, the performance of the explosive with optimized geometry was superior than the standard situation, it has

\section{Table 5}

A comparison between different explosive charge geometries performance

\begin{tabular}{cccc}
\hline Model & $\begin{array}{c}\text { Crater } \\
\text { diameter } \\
(\mathrm{mm})\end{array}$ & $\begin{array}{c}\text { Spall } \\
\text { diameter } \\
(\mathrm{mm})\end{array}$ & $\begin{array}{c}\text { Crater depth } \\
(\mathrm{mm})\end{array}$ \\
\hline $\begin{array}{c}\text { Beppu et al. } \\
{[15]}\end{array}$ & $130-160$ & 210 & $20-28$ \\
$2^{\circ} \begin{array}{c}\text { Simulation } \\
(1 \mathrm{~mm})\end{array}$ & 106 & 200 & 20 \\
$3^{\circ}$ Simulation \\
$\begin{array}{c}(1 \mathrm{~mm}) \\
4^{\circ} \text { Simulation } \\
(1 \mathrm{~mm})\end{array}$ & 166 & 236 & 35 \\
\hline
\end{tabular}

proved efficient by harnessing the explosive energy by channeling it for breaching. However, experiments and more simulations are necessary to verify the applicability of the proposal.

The fourth model has proven that only the contact with the mass of explosive is not sufficient for breaching a concrete slab, it is important to have a suitable arrangement between the surfaces of the explosive and the target to achieve the desired effect.

In the Figure 5 it is possible to see a comparison between the damage level of the models in 2 ms simulation here, the same damage color scale of Figure 4 is used. It's important to note that despite the same mass of explosive charge was used in both cases, the optimized geometry showed a much better performance.

\subsection{Fifth simulation}

In this simulation, the optimized explosive geometry was used (same explosive that was used in the third simulation). However,

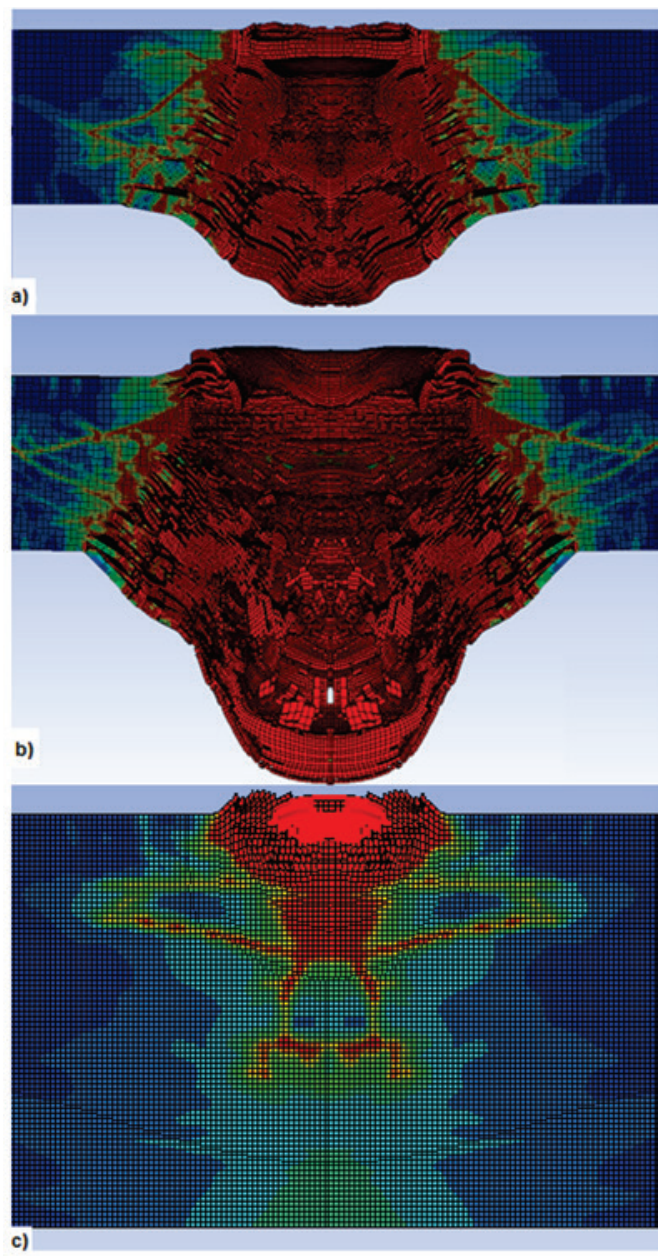

\section{Figure 5}

a) $2^{\circ}$ simulation: explosive with regular dimensions,

b) $3^{\circ}$ simulation: explosive with optimized

dimensions and c) $4^{\circ}$ simulation: explosive with poor dimensions ratio 
Table 6

Results from the fifth simulation

\begin{tabular}{cccc}
\hline Model & $\begin{array}{c}\text { Crater } \\
\text { diameter } \\
(\mathrm{mm})\end{array}$ & $\begin{array}{c}\text { Spall } \\
\text { diameter } \\
(\mathrm{mm})\end{array}$ & $\begin{array}{c}\text { Crater depth } \\
(\mathrm{mm})\end{array}$ \\
\hline $\begin{array}{c}5^{\circ} \text { Simulation } \\
(1 \mathrm{~mm})\end{array}$ & 160 & 300 & 34 \\
\hline
\end{tabular}

the simulated concrete slab is thicker than previous cases, with a thickness of $122 \mathrm{~mm}$.

Table 6 shows the obtained results.

It was observed that use of an explosive with optimized geometry resulted in an expressive breaching of the slab with thickness of 80 $\mathrm{mm}$ and the same explosive was capable of severely damages a thicker concrete slab (122 mm).

It is possible to clearly identify the cratering and spalling regions as shown in Figure 6. In this figure, it is also shown the results of the third simulation that enables a visual comparison between the performance of the same explosive in the perforation of a concrete slab with different thicknesses.

This simulation demonstrated that the explosive mass is not the main parameter to predict with high accuracy the damage in a concrete element. An optimized explosive geometry can be used to breaching or deal critical damage to slabs thicker than that predicted by formulations. However, it is clear that a larger mass of explosive would be required for a more ef-
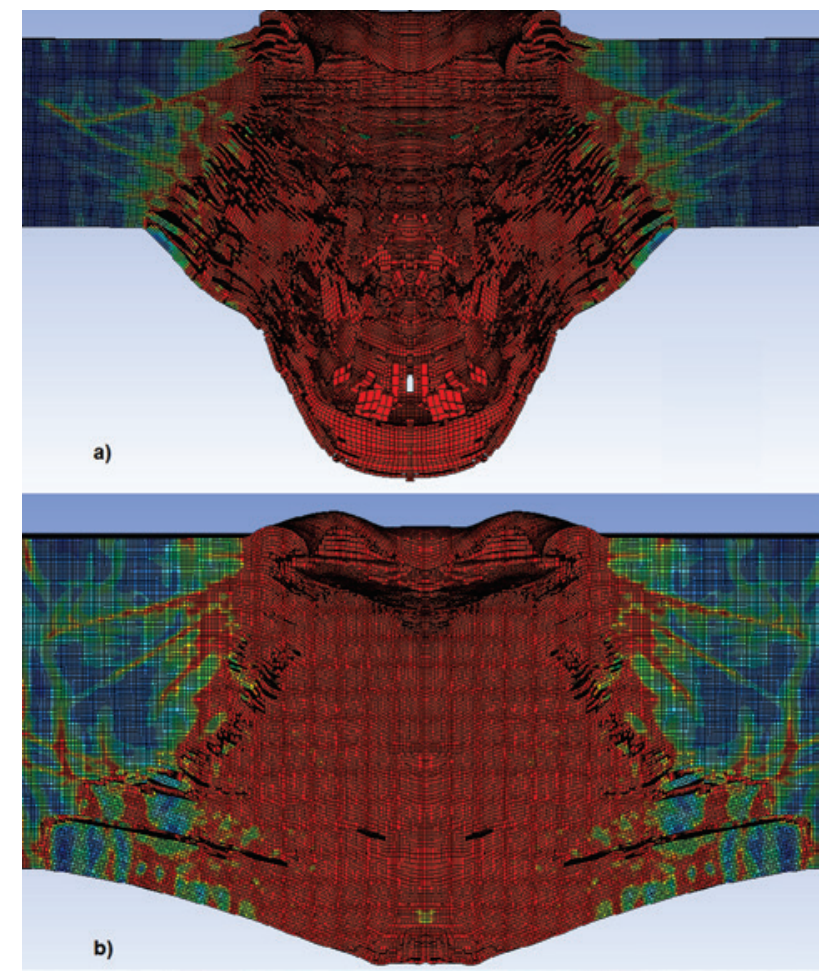

Figure 6

Damage level caused on a concrete slab by the detonation of an explosive with optimized geometry, $3^{\circ}$ simulation (a); $5^{\circ}$ simulation (b) fective breaching of this thicker concrete slab, maybe this points to a destructive potential threshold of the used explosive charge.

\section{Conclusion}

Numerical simulations were developed in this work in order to study the breaching of concrete slabs by an explosive charge.

The first two simulations developed were based on the work of Beppu et al. [15] and the results numerically obtained are very close to those found experimentally. Comparing the different meshes refinement sizes, it was observed that the finest mesh $(1 \mathrm{~mm})$ presented the best results, with a more precise definition of the damage region. Due to the good precision presented, despite the high computational cost, this kind of mesh refinement may be indicated for similar computational modelings.

In the third and fourth simulation, the performance of the "optimized region for breaching" proposal was evaluated. In those cases, the explosive mass was the same but the charge geometry was different.

It was verified in the third simulation, in which the explosive geometry was optimized, that the damage produced in the concrete slab was much higher than the simulated standard situation, which was based on the experiment of Beppu et al. [15] where the ratio of diameter to explosive thickness was 1.

This indicates that an explosive with suitable geometry show an optimized use of detonation energy that channeling a large portion of the detonation products to breaching the slab.

In the fourth simulation, in which was used an explosive with inappropriate dimensions (outside the optimized region for breaching), a significant loss of the energy of the explosion towards the medium was observed, in this way, only a little part of the detonation energy reached the concrete slab that resulted in a little crater (no breaching). It is important to point out that the explosive mass of third and fourth simulations were the same.

Therefore, besides the explosive mass, the explosive geometry showed a significant influence on the energy distribution along concrete surface, this points that explosive geometry is a very important parameter to develop damage prediction studies.

In the fifth simulation, the same explosive of the third simulation was applied, however the concrete slab to be perforated was about $53 \%$ thicker. It was observed that although the slab was much thicker, the explosive with optimized geometry managed to deal a significant level of damage in the concrete slab being possible to identify clearly the zones of cratering and spalling. Nevertheless, a long simulation time would be necessary to clearly capture the final hole dimensions. Considering the same hardware used in previous simulations, its possible to estimate a time around two months to process the complete simulation in order to obtain the final hole dimensions for this case.

The results of this work showed that the proper design of the explosive geometry can guarantee a better use of its detonation energy to breaching. Therefore, the design of explosion-resistant concrete slabs and the development of damage prediction formulae need to take account, in addition to the explosive mass, the explosive geometry and its positioning along the surface of the slab. 


\section{Aknowledgments}

The authors gratefully acknowledge the financial support of the CNPq.

\section{References}

[1] Akers, S. A., Weed, R., Rickman, D. D., Danielson, K. Numerical Simulations of Explosive Wall Breaching, Proceedings of the Users Group Conference, Computer Society, 2005, Denver, USA.

[2] Akers, S. A., Rickman, D. D., Ehrgott, J. Numerical Simulations of Blast Pressures During Wall Breaching, Proceedings of the Users Group Conference, Computer Society, 2006, Denver, USA.

[3] Wu, K. C., Li. B, T, K. C. The effects of explosive mass ratio on residual compressive capacity of contact blast damaged composite columns. Journal of Constructional Steel Research, vol. 67, 2011, pg 602-612.

[4] Li, B., Nair, A., Kai, Q. Residual Axial Capacity of Reinforced Concrete Columns with Simulated Blast Damage. Journal of Performance of Constructed Facilities, ASCE, vol. 26, 2012, 287-299.

[5] Y. Shi, W. Xiong, Z.-X. Li, Q. Xu. Experimental studies on the local damage and fragments of unreinforced masonry walls under close-in explosions. International Journal of Impact Engineering, vol. 90, 2016, 122-131.

[6] F. R. Zhang, C. Q. Wu, H. W. Wang. Y. Zhou. Numerical simulation of concrete filled steel tube columns against BLAST loads. Thin-Walled Structures, vol. 92, 2015, 82-92.

[7] Codina, R. H, Ambrosini, D. Borbón, F. M.. Columnas sometidas a explosiones de campo cercano. XXXVII Jornadas Sudamericanas de Ingenieria Estructural, 2016, Paraguai.

[8] Esteban, B., Gebbeken, N. A comparison of numerical modelling strategies in contact detonation scenarios with concrete targets. Int. J. of Comput. Methods Exp. Meas., vol. 4, nr. 3, 2016, pg 231-246.

[9] Remennikov, A. M., Mentus, I., Uy, B. Explosive breaching of walls with contact charges: theory and applications, Int. J. of Protective Structures, vol. 6, no. 4, 2015, pg 629-647.

[10] Yue, S., Quu, Y, Zhang, N., Wang, M. Analytical study of local damage on concrete slab subjected to a contact explosion, Journal of Vibroengineering, vol. 19, nr. 2, 2017, pg 908-929.

[11] Quan X, Birnbaum N. Computer simulation of impact and collapse of New York World Trade Center north tower on September 11. In: Proceedings of the 20th international symposium on ballistics, 2002, Orlando.

[12] Kim, H., Ahn, J. and Ahn, H.Computational simulation of progressive collapse of reinforced concrete rigid frame with reinforcement contact model. Advances in Structural Engineering, vol. 19, nr. 6, 2016, pg 982-994.

[13] Li, J., Wu, C., Hao, H. and Su, Y. Experimental and numerical study on steel wire mesh reinforced concrete slab under contact explosion. Materials \& Design, vol. 116, 2017, pg 77-91.

[14] Remennikov, A. M., Uy, B. Explosive testing and modelling of square tubular steel columns for near-field detonations, J. Constr. Steel Res., vol. 101, 2014, pg 290-303.
[15] Beppu, M., Ohno, T., Ohkubo, K., Li, B. and Satoh, K. Contact Explosion Resistance of Concrete Plates Externally Strengthened with FRP Laminates. International Journal of Protective Structures, vol. 1, nr. 2, 2010, pg.257-270.

[16] Mays, G. C., Smith, P. D. Blast effects on buildings, Thomas Telford, 1995, Londres.

[17] Millard, S. G., Molyneaux, T. C. K., Barnett,S. J., Gao, X. Dynamic enhancement of blast-resistant ultra high performance fibre-reinforced concrete under flexural and shear loading, Int. J. of Impact Eng., vol. 37, nr. 4, 2010, pg 405-413.

[18] ANSYS Autodyn Interactive Non-Linear Dynamic Analysis software version 15. User's Manual, SAS IP Inc, 2014, USA.

[19] Dobratz, B. M. Properties of Chemical Explosives ans Explosive Simulants, Universidade da Califórnia, UCRL-51319, Laboratório Lawrance Livermore, 1972, EUA .

[20] FM 3-34.214. Explosives and demolitions, Department of the Army, 2007, USA.

[21] Gebbeken, N., Ruppert, M. A new material model for concrete in high-dynamic hydrocode simulations, Arch. Appl. Mech., vol. 70, nr. 7, 2000, pg 463-478.

[22] Anderson Jr., J. D. Computational Fluid Dynamics. McGrawHill series, 1995, USA.

[23] Birnbaum, N. K., Clegg, R. A., Fairlie, G. E. Analysis of Blast Loads on Buildings, Century Dynamics Incorporated, ASME Pressure Vessels and Piping Conference, Structures Under Extreme Loading Conditions, 1996, USA.

[24] Herrmann,W. Constitutive equation for the dynamic compaction of ductile porous materials, J. Appl. Phys., vol. 40, nr. 6, 1969, pg 2490-2499.

[25] Hartmann, T., Pietzsch, A., Gebbeken, N. A Hydrocode Material Model for Concrete, International Journal of Protective Structures, vol. 1, nr 4, 2010, pg 443-468.

[26] Luccioni, B. M., Araoz, G. F., Labanda, N. A. Defining Erosion Limit for Concrete, Int. J. of Protective Structures, vol. 4, nr. 3, 2013, p. 315-340.

[27] Luccioni, B. M., Aráoz, G. Erosion Criteria for Frictional Materials Under Blast Load, Mecánica Computacional, vol. 30, 2011, p. 1809-1831. 